\title{
Awareness Generation among Rural Women for Recycling of Discarded Fabrics to Develop Bio-Fertilizer
}

\author{
Jaymala Dave* and Sudha Babel \\ Department of Textiles and Apparel Designing, College of Community and Applied Science, \\ MPUAT, Udaipur, India \\ *Corresponding author
}

\begin{abstract}
A B S T R A C T
Keywords

Bio-Fertilizer, Discarded Fabrics, Decomposing

Article Info

Accepted:

18 August 2020

Available Online:

10 September 2020

To generate awareness of developed technology among rural women, knowledge test was assessed on the basis of pre and post knowledge of rural women about developed technology. The awareness training programme was launched to sensitize rural women on issues related to developed bio-fertilizer and related aspects. MPSs of the respondents ranged between 75 to 95.83 in post test which indicates good to excellent knowledge in all the components, with the overall knowledge MPS as 91.66. Highest knowledge was possessed by the respondents about concept of developed technology followed by worm bed preparation, watering and earthworms with the rank I, II, III and IV respectively, as reflected by majority of respondents in good category. Further in the remaining components i.e. raw material, pre-treatment \& filling of bed, maintenance of bio-fertilizer, harvesting of bio-fertilizer, care during transportation, uses and advantages indicates good knowledge of respondents in these components also.
\end{abstract}

\section{Introduction}

Management of discarded fabric has become one of the problems we are facing today. The huge amount of discarded fabric generated mostly by textile mills, manufacturing units, boutique, tailor's shop and household sectors. Considerable amount of discarded fabric is dumped in open areas and incinerated after removing small percentage for recycling and reuse. This accumulation of discarded fabric from all over the country causes certain serious environmental problems and health hazards. Looking into the above facts, the researcher got an innovative idea of using these discarded fabric to develop biofertilizer. This grassroots level, replicable, measurable, adoptable, sustainable and economical, innovative idea will be advocated with a holistic approach to the common women that they have organic bio-fertilizer to use. What is most important is the resultant benefit an answer to a global problem of arresting as much of discarded fabric from circulation as possible and converting the dangerous waste into products of utility without intervention of high technology or million dollars investment. This idea will be of great help in preserving and protecting our delicate earth. This innovative idea to 
overcome environmental hazards of discarded fabrics, a biodegradable product, would like to be protector and preserver of mother earth and further generation and immediate environment will be a much better place to live in. The scope of the research encompasses of benefitting the farmers, industrialists, boutiques and tailors shop owners and to the ecology and future generations to come keeping this in view, the present research was conducted in Udaipur city with objective to generation Awareness among rural women about Recycling of discarded fabrics to develop bio-fertilizer.

\section{Materials and Methods}

Sixty rural women were selected to generate awareness and to find out the impact of training in terms of gain in knowledge about developed bio-fertilizer technology. Two villages i.e. Lakawali and Dangiyo ka Guda of Girwa panchayat samitti of Udaipur district were selected from already selected village of the University for convenience. Seven days training was conducted in each village to impart the developed technology. For the training, 30 rural women of 20-35 years of age with lower middle income group were selected on the basis of their interest and willingness to participate in the training in each village. To find out the knowledge of respondents about developed bio-fertilizer technology, knowledge test was used. This test was consist of questions related to concept of bio-fertilizer technology, raw materials, discarded fabrics, vermicomposting, earthworms, water, harvesting of bio-fertilizer, care during transportation, uses and advantages. The questions were close and open ended.

\section{Results and Discussion}

The awareness training programme was launched to sensitize rural women on issues related to developed bio-fertilizer and related aspects. Mean per cent scores on each aspects was calculated and reported below.

\section{Components wise knowledge of developed technology}

An effort was also made to find out the component wise knowledge of the respondents regarding developed technology. Perusal of Table 1 reveals that MPSs of the respondents ranged between 75 to 95.83 in post test which indicates good to excellent knowledge in all the components, with the overall knowledge MPS as 91.66. Closed observation of the table shows that highest knowledge was possessed by the respondents about concept of developed technology followed by worm bed preparation, watering and earthworms with mean percent scores 95.45,94.44,95.45,89.42 respectively and ranked I,II,III and IV respectively, as reflected by majority of respondents in good category. Further the mean percent score in remaining components i.e. raw material, pretreatment \& filling of bed, maintenance of bio-fertilizer, harvesting of bio-fertilizer, care during transportation, uses and advantages ranged between 75 to 95.83 which indicates good knowledge of respondents in these components also.

Results in the Table 1 indicates the knowledge gain of the respondents, that is, rural women regarding the developed technology. The developed technology made up of discarded cotton and silk fabrics using vermin culture. The knowledge gain was measured by distributing it into various subcomponents. The knowledge gain was calculated with the difference between pre and post tests MPS.

\section{Concept of developed technology}

It was encouraging to note that at the time of pre-test 360 scores (54.54\% MPS) were 
obtained while afterwards in post-test it was 630 (95.45\% MPS) and aware about name of the technology. That mean, there was a mean difference between pre and post test (knowledge gain) was 40.90 per cent MPS and it comes under 'I' rank (Table 1). Findings indicated that in post test majority of respondents $(95.45 \%)$ had an understanding about developed technology. Respondents stated that the local name i.e. "Alsia-ki-khad". It is different from the conventional method of preparing compost, i.e. rodi-ki-khad, in the manner that here the bio-fertilizer is prepared by earthworms and gets ready within three months time. It involves, questions related to name of the technology, only heard name, seen established bio-fertilizer unit using vermin-culture technology, interaction with the person preparing and using bio-fertilizer, understanding about bio-fertilizer making technology, prepared by worms and ready in 3 months, various requirements in preparation like shady place, it's raw materials, earth worms, water etc. Each component had its score and the maximum score for this concept was 660 .

\section{Worm bed preparation}

Table 1 interprets that the rank of knowledge gain in this component was 'II'. It can be observed that the second component was "worm bed preparation". In this questions regarding to worm bed preparation i.e. worm bed can be of any size or shape, depending upon the availability and quantity of waste to be composted. Preparation of worm bed is one of the most important aspects of the whole process of bio-fertilizer making. It had 7 subcomponents with their subsequent details and scores. The maximum score of this component was 1080. In pre-test 660 scores (61.11\% MPS) were obtained which was increase in post-test with a remarkable difference range of 1020 scores (94.44\%). The difference in MPS that is knowledge gain was 33.33 per cent.

\section{Raw material}

In vermicomposting, almost all type of biologically degradable and decomposable organic wastes can be used as raw material i.e. animal dung (cattle, sheep, horse, goat and poultry dropping), agriculture waste (large roughage, cereals straws, dry leaves, foliage, husk, leaf litters, coir and processed food waste.), bio-gas slurry, mushroom spent, city garbage, kitchen waste, forestry wastes (wood shavings, peels, saw dust), industrial waste (food processing, distillery), waste paper, cotton and silk fabric, leather, etc. Regarding raw material required for the preparation of bio-fertilizer using vermin culture technology.

It has sub-components with further details as well as their scores. It was found that at the time of pre-test 840 scores $(58.33 \%$ MPS) were obtained while afterwards in post-test it was 1260 (87.50 \% MPS). That mean, there was a mean difference between pre and post test was 29.17 per cent MPS and it comes under 'VII' rank.

The results are in conformity with the results of Kour (2002) that all the farm women had good knowledge about the basic material required for preparing vermicompost such as, animal waste, agriculture waste and green neem leaves.

\section{Earthworms and their feedstock}

Earthworms have intrinsic capabilities for physiological, behavioural and biochemical adoptions. They can even detoxify the soil. There are over three thousands species of earthworms. It is important to select right type of earth worm species to have optimal results. In general, country like India, species to be used for vermin-composting should have high temperature- tolerance and high growth rate (protein conversion). In lieu of above points, the popularity used species with fasts growing 
nature is Eisenia foetida. The data revealed that in Table 1, the results of the fourth component "earthworms" were also worth obvious. The maximum score for this was 1740. The gain in knowledge of rural women was ranked 'IV' with 31.55 per cent MPS. In pre-test scores obtained were 1007 (57.87\% MPS) while the scores of post-test were 1556 (89.42\% MPS).

\section{Watering of bed}

Watering of bed is an important activity in preparation of vermin-compost. It creates moist and cold condition for earthworms, essential for compost and to increase vermin activities. It also makes raw material soft and eatable for earthworms, protect them from its enemies especially from ants \& white ants. Water is used for preparation of vermincompost should be clean and free from chemicals, insecticide and soap. It is clear from Table 1 that fifth and important component was "role of water" with its minute facts like what type of water is used and its season wise requirement etc. It had maximum score of 660 . The result indicated that in pre-test 420 scores $(63.63 \%$ MPS) were obtained which was increase in post-test with a remarkable difference range of 630 scores $(95.45 \%)$. The difference in MPS that is knowledge gain was 31.82 per cent and it comes under 'III' rank.

\section{Pretreatment and filling of beds}

In the pre test 66.66 percent and in post test 95.83 percent respondents knew about the pre-treatment of bed, to make bed free from insects, harmful for earthworms like termite $\&$ ants. Data of Table 1, also shows that sixth component was "pre-treatment and filling of beds" further had particulars with maximum scores of 720. The gain in knowledge of rural women was ranked 'VII' with 29.17 per cent MPS. In pre-test scores obtained were 480
(66.66\% MPS) while the scores of post-test were 690 (95.83\% MPS).

\section{Maintenance of worm bed}

It is depicted in the Table 1 that "Maintenance of worm bed" was the seventh component. Regarding maintenance of worm bed questions related to daily watering of bed, excess watering should be avoided as it creates anaerobic conditions, 2-3 months are required for the preparation of bio-fertilizer through vermin-composting, ready when it turns to black in colour, granular in form and non sticky matter, becomes light in weight in local terms 'Nailo' and becomes odourless etc. It has further information to be asked from the respondents and had maximum score of 960 . It was recorded that at the time of pretest 600 scores $(62.50 \%$ MPS) were obtained while afterwards in post-test it was 900 (93.75 $\%$ MPS) and aware about concept of developed technology. That mean, there was a mean difference between pre and post test was 31.25 per cent MPS and it comes under ' $\mathrm{V}$ ' rank.

\section{Harvesting the bio-fertilizer}

Bio-fertilizer is ready for harvesting or collection, when the top layer appears somewhat 'dark brown' or 'black' color granules. The data heralds in Table 1 that eighth component was "harvesting the biofertilizer" which had 1020 maximum score to obtainable with its fine facts. Pre-test scores 600 (58.82 \% MPS) were defeated by posttest scores 900 (88.23\% MPS) with rank 'VI'.

\section{Care during transportation}

Care of earthworms during transportation that is the mouth of gunny bag or plastic bag should not be closed, the feed and water should be sprinkle as per requirement. Table 1 
deals with care during transportation there were further particulars also with maximum score of only 120 . Only 50 per cent MPS was found at the time of pre-test but it was beaten up by the post-test scores of 90 (75\% MPS). It had 25 per cent MPS mean difference as gain in knowledge. The rank of this component's result was 'IX' (Fig. 1).

Table.1 Percentage distribution of the respondents by components wise knowledge gain $n=60$

\begin{tabular}{|c|c|c|c|c|c|c|c|c|}
\hline \multirow[t]{2}{*}{ S.No } & \multirow[t]{2}{*}{ Components } & \multirow[b]{2}{*}{$\begin{array}{l}\text { Total } \\
\text { Score }\end{array}$} & \multicolumn{2}{|c|}{ Pre-Test } & \multicolumn{2}{|c|}{ Post -Test } & \multirow{2}{*}{$\begin{array}{c}\text { Knowledge } \\
\text { Pre and Post } \\
\text { MPS }\end{array}$} & \multirow[t]{2}{*}{ Rank } \\
\hline & & & $\begin{array}{c}\text { Score } \\
\text { obtaine }\end{array}$ & MPS & $\begin{array}{c}\text { Score } \\
\text { obtained }\end{array}$ & MPS & & \\
\hline 1. & Concept & 660 & 360 & 54.54 & 630 & 95.45 & 40.90 & I \\
\hline 2. & Worm bed preparation & 1080 & 660 & 61.11 & 1020 & 94.44 & 33.33 & II \\
\hline 3. & Raw Material & 1440 & 840 & 58.33 & 1260 & 87.50 & 29.17 & VII \\
\hline 4. & Earthworms & 1740 & 1007 & 57.87 & 1556 & 89.42 & 31.55 & IV \\
\hline 5. & Watering of bed & 660 & 420 & 63.63 & 630 & 95.45 & 31.82 & III \\
\hline 6. & $\begin{array}{l}\text { Pre-treatment \& filling of } \\
\text { bed }\end{array}$ & 720 & 480 & 66.66 & 690 & 95.83 & 29.17 & VII \\
\hline 7. & $\begin{array}{l}\text { Maintenance of bio- } \\
\text { fertilizer }\end{array}$ & 960 & 600 & 62.50 & 900 & 93.75 & 31.25 & V \\
\hline 8. & Harvesting of bio-fertilizer & 1020 & 600 & 58.82 & 900 & 88.23 & 29.41 & VI \\
\hline 9. & Care during transportation & 120 & 60 & 50 & 90 & 75 & 25 & IX \\
\hline 10. & Uses and advantages & 1560 & 1040 & 66.66 & 1454 & 93.20 & 26.54 & VIII \\
\hline
\end{tabular}

Table.2 Distribution of the respondents on the basis of their overall knowledge about developed technology $n=60$

\begin{tabular}{|l|l|l|c|c|c|c|}
\hline S. & \multicolumn{2}{|l|}{ Knowledge Categories } & \multicolumn{2}{|c|}{ Pre-Test } & \multicolumn{2}{c|}{ Post-Test } \\
\cline { 3 - 7 } No. & & Number & Number & \% \\
\hline $\mathbf{1}$ & Poor & $(0-33.33)$ & 19 & 45.46 & 0 & 0.00 \\
\hline $\mathbf{2}$ & Average & $(33.34-66.66)$ & 41 & 54.54 & 7 & 8.34 \\
\hline $\mathbf{3}$ & Good & $(66.67-100)$ & - & - & 53 & 91.66 \\
\hline
\end{tabular}

Fig.1 Awareness training conducted

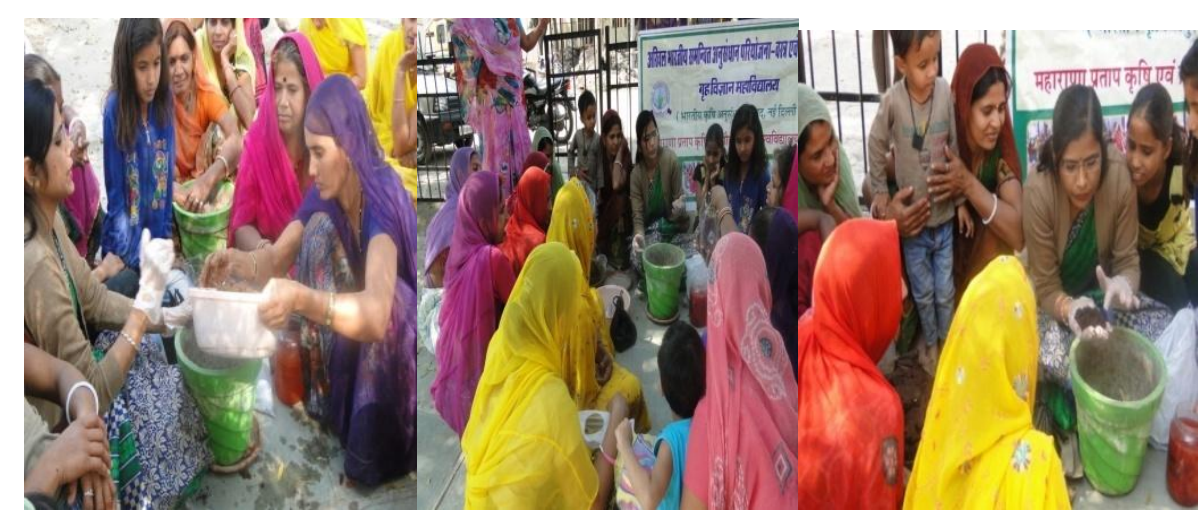




\section{Uses and advantages of bio-fertilizer}

Prepared bio fertilizer can be used as top dressing in crops, use in ornamental plants, lawns and kitchen gardens. As per the data shown in Table 1, last component consists of the uses and advantages of bio-fertilizer with further detail information having maximum score of 1560 . Its results were equivalent to 'VIII' rank having 26.54 per cent mean difference MPS of pre and post test knowledge. The pre-test scores were 1040 (66.66 \% MPS) which were covered up in post-test with 1454 scores (93.20\% MPS).

\section{Overall knowledge of developed technology among the respondents}

Further an effort was made to categorize the respondents on the basis of their overall knowledge about developed technology. Findings in Table 2 show that in pre- test respondents had poor knowledge $(45.46 \%)$ and average knowledge (54.54\%) about developed technology and in post test respondents had average knowledge (8.34\%) and good knowledge (91.66\%).In pre test, none of them were in the category of good and in post test none of them were in the category of poor.

A study conducted by Kour (2002) supported the results that all the respondents had good knowledge about vermin-culture technology which is indicated from mean percent knowledge score (85.04). From the research study it can be concluded that respondents had good knowledge about developed technology. The possible reasons for good knowledge among respondents might be the effective trainings, regular visits and follow up at village. This study has shown a need to improve the knowledge about developed technology to protect environment from negative impact of waste. It is recommended to implement the need based training programme for rural women. The use of bio-fertilizer also beneficial for soil loss $\&$ degradation

Hence, it can be concluded that the discarded fabric collected from tailors shop and boutiques which is not utilized for any products before can be recycled into bio-fertilizer that can be economical and sustainable. Marketing of cotton and silk bio-fertilizer know potential and flourishing Industry due to the growing awareness among the people about the ill effect of chemical fertilizer and the relative benefit of organic farming. The utilization of cotton and silk bio-fertilizer results in several benefits to farmers, industries, environment and overall national economy.

\section{References}

Kour, P. 2002. Evaluation of vermiculture technology transfer programme among rural women in terms of knowledge and adoption. M.Sc. thesis submitted to Maharana Pratap University of Agriculture and Technology. Udaipur. Rajasthan.

Gupta, P., Singh, S. and Singhal, A. 2000. Promotion of agro- based enterprise among farm women under NATP. Proceedings of natural seminar on micro enterprise in rural India- experience, prospect and strategies, held at New Delhi from 18-19 Nov, 2004, 80.

Garg, V.K., Gupta, R. and Yadav, A. 2005. Vermicomposting technology for solid waste management. Department of Environmental Science and Engineering Guru Jambheshwar University of Science and Technology Hisar.

\section{How to cite this article:}

Jaymala Dave and Sudha Babel. 2020. Awareness Generation among Rural Women for Recycling of Discarded Fabrics to Develop Bio-Fertilizer. Int.J.Curr.Microbiol.App.Sci. 9(09): 2801-2806. doi: https://doi.org/10.20546/ijcmas.2020.909.346 